\begin{tabular}{|c|c|c|}
\hline & PORT-SAID ENGINEERING RESEARCH JOURNAL
\end{tabular}

\title{
Neural Network Model of Carbon Monoxide Distribution in Onboard a RO-RO Ship Garage
}

\author{
H. Agamy ${ }^{1}$, M. Mosleh ${ }^{2}$, K. Elserafy ${ }^{3}$, M. Abdel Geliel ${ }^{4}$ and N. Abdel Rahman ${ }^{5}$
}

\begin{abstract}
Exhaust emissions in the closed vehicle garage onboard ships not sufficiently ventilated can cause damage to human health and lead even to death and pollution. In this paper, an intelligent artificial neural network model is designed to simulate the carbon monoxide concentration in order to be used to manage the concentration limits in the permissible range. The proposed model is identified based on data collected from real measurements at different load conditions and positions on a Roll-on/Roll-off (RO-RO) vehicle garage onboard a ship vessel. The neural network model is designed, identified and verified to cover all possible operating conditions at different loading and distribution of cars.
\end{abstract}

Keywords: Indoor Air Quality, Carbon monoxide concentration, Artificial Neural Network

\section{INTRODUCTION}

Indoor air pollution has become a major concern of the general publics in recent years. Indoor exposure may likely cause more harmful health effects, as the indoor concentrations of many pollutants are often higher than those typically encountered outside. The factors affecting the indoor environment mainly include temperature, relative humidity, ventilation, particle pollutants, biological pollutants, and gaseous pollutants. Ventilation and source control are the two basic engineering tools for improving indoor air quality. Source control is the most effective strategy for maintaining clean indoor air, however, it is not always possible or practical. Ventilation, either natural or mechanical, is the second most effective approach to provide acceptable indoor air quality.

Numerous research studies exist regarding pollutant dispersion in a variety of interior working environments, such as underground parking garages [1], road tunnels [2], train stations [3], public transport interchange stations [4,5], schools [6], cinemas and airports [7]. However, very scarce references are focusing on the potential occupational safety hazards based on carbon monoxide (CO) concentration levels in ship vehicle garages.

\footnotetext{
${ }^{l}$ Institute of Maritime Upgrading Studies, AASTMT, Alexandria, Egypt, E-mail: hnagamy@hotmail.com

${ }^{2}$ Faculty of Engineering, Alexandria University Alexandria, Egypt, Email: momosleh@alexu.edu.eg

${ }^{3}$ Faculty of Engineering, Electric Dept., Port Said University, Egypt, Email: relserafi@hotmail.com

${ }^{4}$ Electrical and Control Engineering Dept., AASTMT, Alexandria, Egypt, E-mail: maelgeliel@yahoo.com

${ }^{5}$ College of Marine Engineering, AASTMT, Alexandria, Egypt, E-

mail: nasr_abdalrahman@yahoo.com
}

The ventilation system, for enclosed vehicle garage onboard ships, used to be designed to meet International Maritime Organization (IMO) firefighting standards discarding the air quality for workers [8]. Carbon monoxide ( $\mathrm{CO}$ ) concentration is believed to be the most important chemical species to be considered in designing ventilation systems for car parks, because of its harmful effect and may be deadly on human health [9-10].

Thus, IMO new requirement is controlling the $\mathrm{CO}$ concentration to eliminate its harmful threats, also according to IMO regulations in closed spaces for vehicles (i.e. in garages) one sensor should cover an area of $900 \mathrm{~m}^{2}$ [8]. Based on the survey results [11-13], a mathematical model of the place to be ventilated in the ship is required. It is difficult to obtain an analytical model, so artificial intelligence model is appropriate.

Artificial Neural Network (ANN) has an ability to learn how to do tasks based on the data given for training or initial experience. During learning time, ANN can further create its individual organization or representation of the information it receives. Artificial neural networks provide iterative on-line learning schemes for modeling non-linear systems.

Accordingly, the purpose of this study is to build an Artificial Neural Network (ANN) model to simulate the carbon monoxide concentration in a high-speed craft passenger/RO-RO ship vehicle garage, explained in case study section 2, and validate it. That is because of ship workers are subjected to high $\mathrm{CO}$ concentration levels while loading and unloading cars for many hours. 


\section{CASE STUDY: A RO/RO SHIP VEHICLE GARAGE}

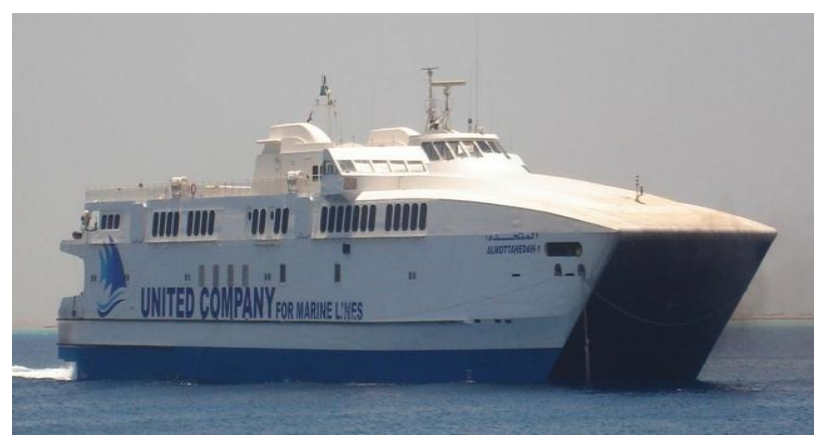

Fig. 1 RO-RO ship

A RO-RO ship vehicle garage contains two decks, main deck and the upper deck as shown in Fig. 1. The dimensions of the main deck are $70 \mathrm{~m}$ long $\mathrm{x} 23 \mathrm{~m}$ wide $\mathrm{x}$ $2.8 \mathrm{~m}$ height. It can load up to 70 cars +8 buses. The upper deck is a U-shaped corridor with one ramp at each end. Its dimensions are $119 \mathrm{~m}$ long $\times 7 \mathrm{~m}$ wide $\times 2.2 \mathrm{~m}$ height. It can load up to 62 cars. Both decks are in the same interior, which means there are no separations between them. The study is concerned with the main deck. Based on previous studies, data is collected from real measurements at different load conditions, different positions and different types of ventilation[14]. This data were studied using computational fluid dynamics (CFD) in order to characterize the carbon monoxide diffusion patterns inside a ship's vehicle garage as mentioned in [14]. These measurements are divided into input data and output data. This data is used to generate an ANN model. The input and output data are shown in Appendix [1].

\section{1) Input data}

The sensors in the main deck aredistributed as in Fig., according to length, width and height. This data is for the main deck of the garage. It has been arranged according to the variable loads, which are $15 \%$ of the cars loaded and $20 \%$ of the car loaded and at last $25 \%$ of the car loaded which is the maximum loaded as recommended by IMO. Also, the table shows the location of the sensors distributed in the garage i.e. $\mathrm{X}, \mathrm{Y} \& \mathrm{Z}$ directions but the $\mathrm{Z}$ direction is at $1.5 \mathrm{~m}$ from ground (breathing zone). Then the kind of ventilation is showed, we have four different situations. first situation is with normal ventilation of the rear ventilators working at 10 air change per hour( $\mathrm{ACH})$ as recommended by IMO of the garage i.e. no vent. The second one is normal ventilation of the rear ventilators and an extra ventilator but working as suction ventilator, third one is normal ventilation of the rear ventilators plus a normal ventilator fan which is delivering air inside and the last one is normal ventilation of the rear ventilators plus the ventilator fan is given a 45-degree angle to help more in ventilation.

\section{2) Output data}

The output data represents the concentration of the $\mathrm{CO}$ measured.

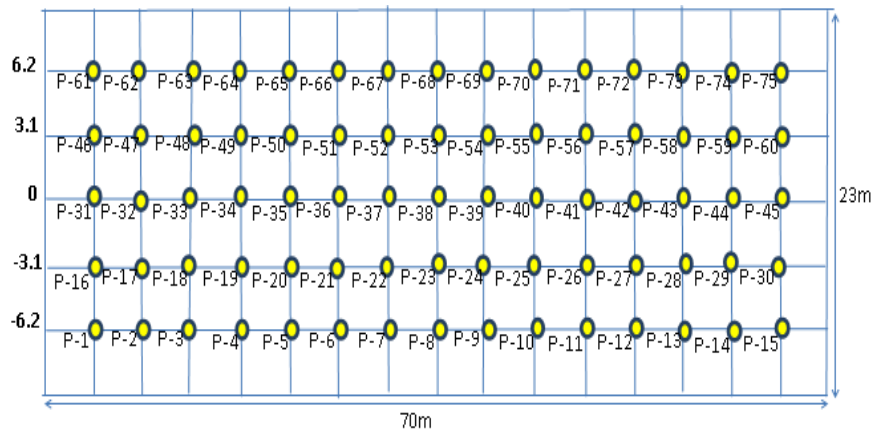

Fig. 2 The main deck sensor distribution

\section{3) Preparing main data:}

First, data is divided to two subsets, one representing the input and the other representing the output. Each subset is normalized; thus, the data range will be all in the range from $0-1$. Applying these two subsets to the Matlab software to run the ANN model and see the effect of its performance. The performance can be known from regression output, if it is close to 1 then, the error is minimum.

Correspondingly, the ventilation type will be converted to binary format to make it easy to understand the different cases of ventilation. No side vent in the garage is given digit " 0 " if it is " 1 " means there is a side vent. Suction/ delivery if " 0 " means the vent is delivering air, but if "1" means exhausting out air from garage. Eventually, angle means that the side vent is at 45 degree, if" 0 " then there is no angle but if " 1 " means that there is an angle.

\section{NEURAL NETWORK MODELING}

The neural network usually consists of an input layer, some hidden layers and an output layer. In its simple form, each single neuron is connected to other neurons of a previous layer through adaptable synaptic weights. Knowledge is usually stored as a set of weights. Training is the process of obtaining the weights using a suitable learning method.

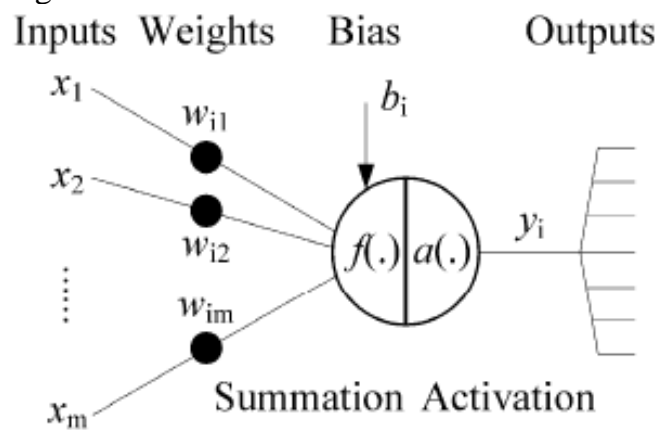

Fig. 3 Neuron Output

The output of the neuron as in Fig. 3 is given by:

$$
\begin{aligned}
& y(t+1)=a\left(\sum_{j=1}^{m} w_{i j} x_{j}(t)-b_{i}\right) \\
& f_{i}=\sum_{j=1}^{m} w_{i j} x_{j}-b_{i}
\end{aligned}
$$


Where:

$y_{\mathrm{i}}$ is the output of the neuron

$x=\left(x_{1}, x_{2}, . x_{m}\right)$ represents the $m$ input applied to the neuron,

$w_{i j}$ represents the weights for input $x_{i}$,

$b_{i}$ is a bias value,

$a($.$) is activation function.$

$\mathrm{f}($.) is pre-activation function

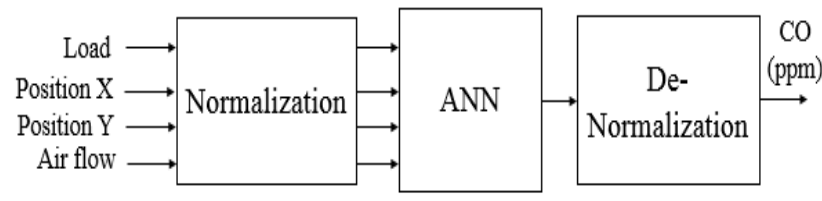

Fig. 4 ANN block diagram

In the proposed case study, model of the ship as in Fig. 4 is a nonlinear model with unknown parameters in the form of

$$
\mathrm{CO}=\mathrm{f}\left(\mathrm{L}_{2}, \mathrm{P}, \mathrm{V}\right)
$$

where,

\section{$L \in R$ : percentage Loading of cars \\ $P=\{x, y\}, P \in R^{2}:$ meausuring position $x$ and $y$ direction \\ $V \in R$ : Air flow rate}

So, the ANN model used is

$$
C O=f_{A N X}\left(L_{2} P_{a}, V_{s} W_{s} B\right)
$$

$$
W \in R^{m} \times R^{z}
$$

$$
B \in R^{z}
$$

where,

$$
\begin{aligned}
& \text { m: Number of inputs for all neurons } \\
& \text { z: Total number of neurons } \\
& \text { B: Bias of neurons } \\
& \text { W: Weight between neurons }
\end{aligned}
$$

For the neural network to be an accurate model of the problem to be learned, a suitable number of hidden neurons are needed. The number of hidden neurons depends upon the degree of nonlinearity of input-output relationship. They can be known by either experience or a trial-and-error process.

The construction of ANN model in Fig. 5 consists of four layers input layer, output layer and two hidden layers. Six neurons (load, position X, position $\mathrm{Y}$, and three digits representing the fan direction) are in the input layer. In the two hidden layers, the first layer has six neurons, the second layer has four neurons. The output layer contains one neuron for $\mathrm{CO}$ concentration. The
ANN model structure on Matlab/Simulink is a feedforward backpropagation type network selected with a training function that updates weight and bias values according to Levenberg-Marquardt optimization. The ANN model structure with the transfer functions for all layers are PURELINE transfer function.

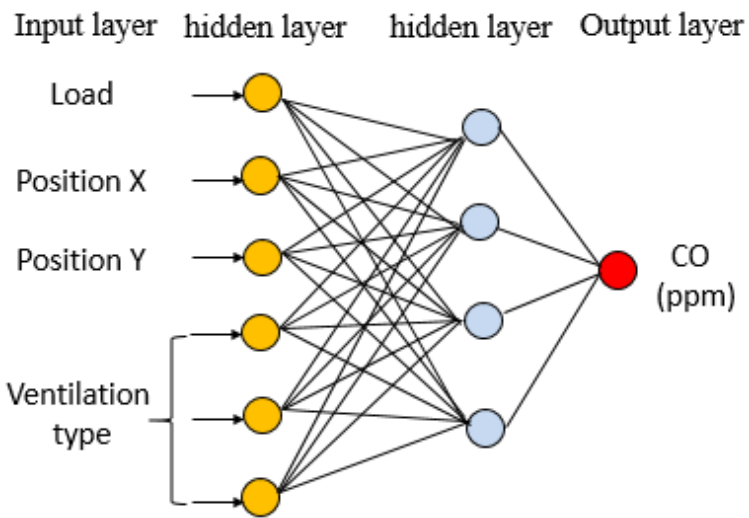

Fig. 5 ANN Model Network design

By applying input and output data to the proposed model and monitor the output, its regression reaches $57 \%$, which means unaccepted behaviour.

\section{IDENTIFICATION OF MODEL}

According to the amendments of IMO, one sensor can cover $900 \mathrm{~m}^{2}$ and there are 75 points of sensing. Average concept will be tried to reduce number of sensing points. The main data are averaged by several ways, to investigate the best way to represent the main data. The data is redesigned, divided into input and output files, normalized then tested through the ANN model to investigate if the minimum error is achieved or not. The minimum error could be known from the coefficient of determination produced as an output from the Matlab/Simulink. As the coefficient of determination (regression) is near to one as the error is minimum.

Table 1 displays the different data groups, number of zones, number of points in each zone and regression. From results, it can be remarked that all models are not significant except the $4 \times 4$ which is $90 \%$ accurate may represent the data but not enough accuracy.

Table 1 Regression of different models

\begin{tabular}{|c|c|c|c|}
\hline Data groups & No. of zones & Points/zone & Regression \\
\hline All & 1 & 75 & $57.13 \%$ \\
\hline $2 \times 8$ & 8 & 16 & $78.80 \%$ \\
\hline $4 \times 4$ & 10 & 16 & $90.02 \%$ \\
\hline $2 \times 2$ & $4 \times 7$ & 4 & $75.29 \%$ \\
\hline
\end{tabular}

Changing the parameters of the ANN by increasing number of layers (to facilitate computation) and/or increasing the number of neurons (to increase accuracy) according to data available. The best ANN configuration based on the learning results using feed forward back propagation technique 
Since the ventilation type of input data is discrete, it has to be continuous in order to use this model in control process, the variable cases of ventilation will be changed. Thus, no vent will be " 0 ", suction is eliminated because it has the worst results, side vent will be " 0.5 " and 45 angles will be"1" representing rate of flow(speed)of fan. Therefore, instead of 6 input variables, there will be 4 input variables. Consequently, the ANN model that gives minimum error is shown in Fig. 6.

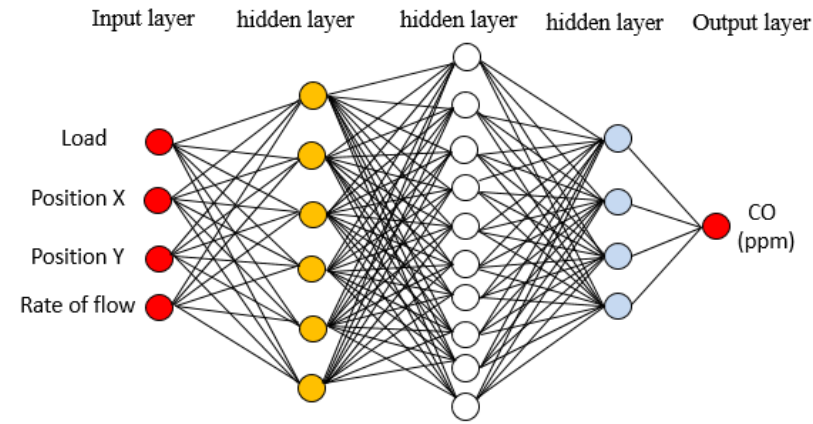

Fig. 6 Proposed ANN model

So, construction of the proposed ANN model consists of five layers; input layer, output layer and three hidden layers. Four neurons (load, position X, position Y, and fan speed) are in the input layer. In the three hidden layers, the first layer has six neurons, the second layer has ten neurons and the last layer has four neurons. The output layer contains one neuron for $\mathrm{CO}$ concentration. The LOGSIGMOID transfer function is used for the three hidden layers and TANSIGMOID for output layer. The learning algorithm is carried by the feed forward backpropagation technique. The results of simulation are shown in Fig. 7.

The regression is about $96.6 \%$ which is a very good representation and high accuracy. So, this model shows the best performance of the neural network model which obtained after 6 epochs.
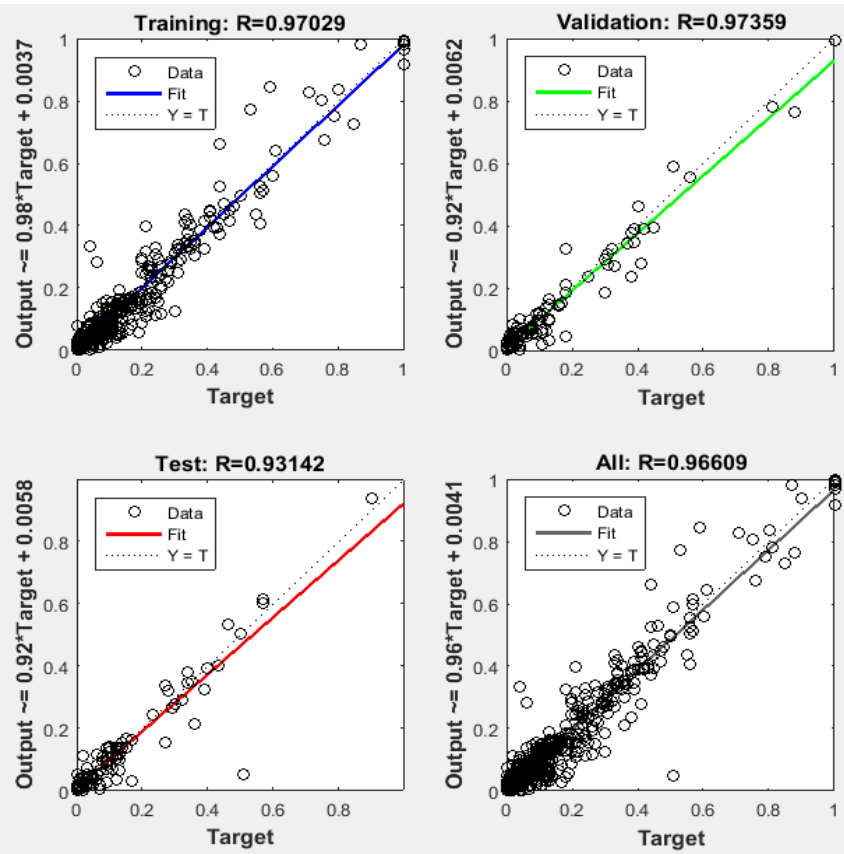

Fig. 7 Regression of ANN model

\section{VALIDATING THE MODEL}

New subset of data was used to validate the model which consists of 153 points at different positions on the same plane and loading conditions [14]. The Data are normalized and applied to the proposed ANN model.

Fig. 8 shows the regression of 153 point about $98.7 \%$ which indicated that the model is well represented and validated.
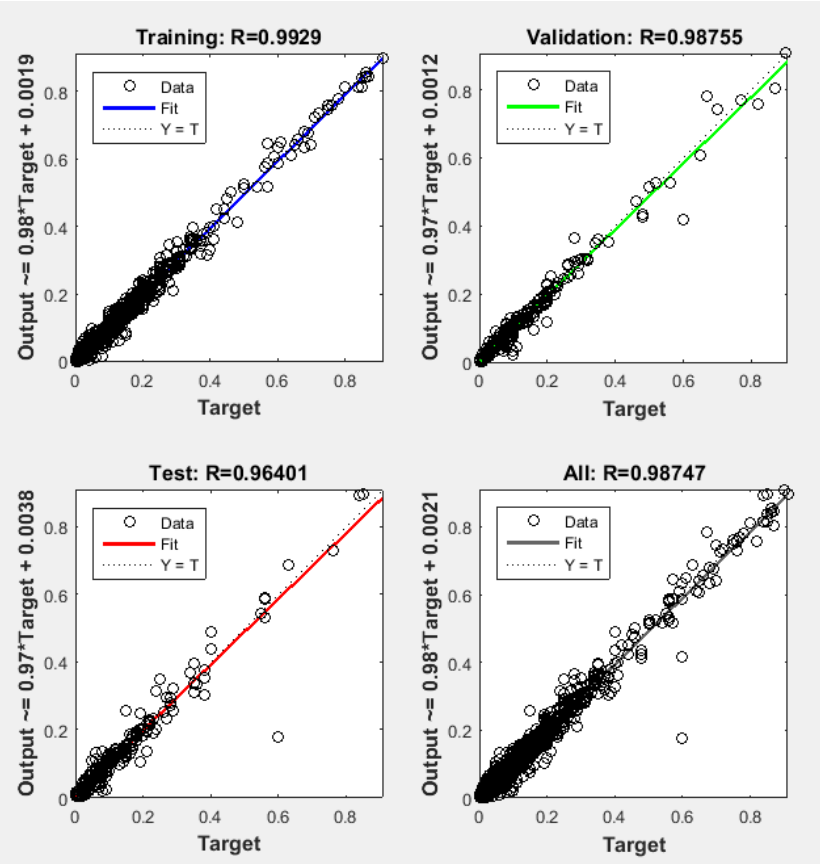

Fig. 8 Regression of ANN model 


\section{CONCLUSION}

An ANN model to simulate the CO concentration at different conditions for RO-RO ship is designed. The proposed ANN model is tested at different individual points and merging points with different ANN properties using MATLAB/SIMULINK. In each case, the simulation outputs are differentiated with the measured outputs to judge on the regression and performance of the model.

It has been concluded that the ANN model shows significant outputs with a high accuracy reaches $96.6 \%$ considering , 75 points, five layers, using LOGSIGMOID transfer function for the three hidden layers and TANSIGMOID for output layer, feed forward backpropagation technique as learning algorithm. The model is validated using new data and shows a significant output of $98.7 \%$.

In future, the proposed ANN model can be controlled with a fuzzy controller to minimize the $\mathrm{CO}$ concentration according to the load. This model is based on static data and has approximation so this validation algorithm can be used online to enhance the model to overcome the dynamic and approximation problem.

\section{REFERENCES}

1. Duci A., Papakonstantinou K., Chaloulakou A. and Markatos N., "Numerical approach of carbon monoxide concentration dispersion in an enclosed garage". Building and Environment 2004; 39, $1043-$ 1048.

2. Bari S. and Naser J., "Simulation of smoke from a burning vehicle and pollution levels caused by traffic jam in a road tunnel". Tunneling and Underground Space Technology (2005), 20, 281290.

3. Chiam H. B., "Numerical Simulation of a Metro Train Fire". M.Sc. Thesis, University of Canterbury (2005).

4. Bateman D. N., (2007), "Carbon Monoxide", Medicine 35, 604-605.

5. Lin Z., Jiang F., Chow T.T., Tsang C.F. and Lu W.Z.Z., "CFD analysis of ventilation effectiveness in a public transport interchange". Building and Environment (2006), 41, 254-261.

6. Chaloulakou.A., Duci. A and Spyrellis. N "Exposure to carbon monoxide in enclosed multi-level parking garages in the central Athens urban area", Indoor and Built Environment 11 (2002) 191-201.

7. Webb A., "FDS Modeling of Hot Smoke Testing, Cinema and Airport Concourse". M.Sc. Thesis, Worcester Polytechnic Institute (2006).

8. IMO "Development of amendments to SOLAS regulation II-2/20 and associated guidance on air quality management for ventilation of closed vehicle spaces, closed RO-RO and special category spaces" IMO- Maritime Safety Committee 1st session Agenda item 6 - 3 December 2015.
9. Goyal, S., Ingley, H. A. and Barooah, P. (2013) 'Occupancy-based zone-climate control for energyefficient buildings: Complexity vs. performance', Applied Energy, 106, pp. 209-221. doi: 10.1016/j.apenergy.2013.01.039.

10. Griffin M., and MD., et al. "Diesel Fumes Do Kill. A Case of Fatal Carbon Monoxide Poisoning Directly Attributed to Diesel Fuel Exhaust with a 10-year Retrospective". J Froensic Sci, September 2008 Vol. 53. No.5

11. Behrang Chenari, João Dias Carrilho, Manuel Gameiro da Silva "Towards sustainable, energyefficient and healthy ventilation strategies in buildings: A review", Renewable and Sustainable Energy Reviews, Volume 59, June 2016, Pages 1426-1447

12. Kim S. S., Lee Y. G "Field measurements of indoor air pollutant concentrations on two new ships" Building and Environment (2010), 45, 2141-2147.

13. Y. Song, S. Wu and Y. Y. Yan, "Control strategies for indoor environment quality and energy efficiency-a review", International Journal of LowCarbon Technologies 2015, 10, 305-312

14. N. A. Nasr, A. F. Elsafty and M. Mosleh "CFD Investigation of Carbon Monoxide Concentration within a Ship Vehicle Garage", the American Society of Mechanical Engineering conference (ASME 2013). 
Appendix 1

\begin{tabular}{|c|c|c|c|c|c|c|c|c|c|c|c|c|c|c|c|}
\hline \multirow{2}{*}{$\begin{array}{c}\text { Surve } \\
\text { y point }\end{array}$} & \multicolumn{3}{|c|}{ Coordinates (m) } & \multicolumn{3}{|c|}{$\begin{array}{c}\text { No side vents } \\
\text { (loading conditions) }\end{array}$} & $\begin{array}{r}\mathrm{S} \\
\text { (load }\end{array}$ & $\begin{array}{l}\text { le suctio } \\
\text { ng condi }\end{array}$ & s & $\begin{array}{r}\text { an } \\
\text { (loa }\end{array}$ & $\begin{array}{l}\text { e side } v \\
\text { g cond }\end{array}$ & $\begin{array}{l}\text { ts } \\
\text { ons) }\end{array}$ & $\begin{array}{l}45^{\circ} \text { a } \\
\text { (load }\end{array}$ & $\begin{array}{l}\text { gle side } \\
\text { g cond }\end{array}$ & $\begin{array}{l}\text { ents } \\
\text { ons) }\end{array}$ \\
\hline & $\mathbf{X}$ & $\mathbf{Y}$ & $\mathbf{Z}$ & $15 \%$ & $20 \%$ & $25 \%$ & $15 \%$ & $20 \%$ & $25 \%$ & $15 \%$ & $20 \%$ & $25 \%$ & $15 \%$ & $20 \%$ & $25 \%$ \\
\hline P-1 & 8.88 & -6.2 & 1.5 & 35.28 & 41.96 & $\begin{array}{l}64.98 \\
\end{array}$ & 41.69 & 51.33 & 70.41 & 28.66 & 37.96 & 53.43 & 23.7 & 33.93 & 50.18 \\
\hline $\mathrm{P}-2$ & 12.96 & -6.2 & 1.5 & 40.32 & 51.32 & 70.22 & 56.29 & 63.45 & 98.81 & 37.8 & 47.9 & 62.92 & 25.03 & 36.26 & 53.15 \\
\hline P-3 & 17.04 & -6.2 & 1.5 & 30.14 & 40.03 & 69.29 & 39.41 & 50.88 & 72.13 & 22.58 & 36.12 & 58.76 & 18.48 & 29.91 & 46.78 \\
\hline P-4 & 21.12 & -6.2 & 1.5 & 28.94 & 41.14 & 54.84 & 39.45 & 55.42 & 70.44 & 18.18 & 31.01 & 53.64 & 14.15 & 22.98 & 39.26 \\
\hline P-5 & 25.2 & -6.2 & 1.5 & 31.83 & 59.38 & 60.85 & 54.39 & 74.98 & 82.56 & 16.43 & 34.35 & 54.63 & 15.3 & 26.96 & 38.86 \\
\hline P-6 & 29.28 & -6.2 & 1.5 & 19.86 & 28.22 & 41.22 & 37.51 & 48.84 & 56.93 & 10.31 & 21.26 & 35.02 & 9.03 & 19.49 & 26.17 \\
\hline P-7 & 33.36 & -6.2 & 1.5 & 19.78 & 27.44 & 37.32 & 39.73 & $\begin{array}{l}52.34 \\
\end{array}$ & 75.18 & 9.35 & $\begin{array}{l}18.9 \\
\end{array}$ & 28.2 & 8.81 & 16.26 & 23.3 \\
\hline P-8 & 37.44 & -6.2 & 1.5 & 17.8 & 24.64 & 26.82 & 36.78 & 41.89 & 63.84 & 8.5 & 15.74 & 24.5 & 7.02 & 13.56 & 20.75 \\
\hline P-9 & 41.52 & -6.2 & 1.5 & 11.31 & 20.97 & 24.28 & 24.56 & 37.61 & 43.3 & 6.41 & 13.67 & 17.92 & 5.85 & 11.93 & 15.67 \\
\hline P-10 & 45.6 & -6.2 & 1.5 & 11.92 & 20.86 & 25 & 18.78 & 28.87 & 36.31 & 6.73 & 14.14 & 18.44 & 6.4 & 13.58 & 17.47 \\
\hline P-11 & 49.68 & -6.2 & 1.5 & 12.78 & 21.53 & 23.23 & 19.44 & 28.13 & 37.8 & 9.12 & 16.55 & 19.5 & 9.01 & 15.93 & 18.48 \\
\hline P-12 & 53.76 & -6.2 & 1.5 & 23.04 & 30.63 & 33.25 & 26.79 & 37.16 & 43.21 & 13.19 & 25.73 & 29.38 & 12.38 & 22.18 & 26.21 \\
\hline P-13 & 57.84 & -6.2 & 1.5 & 24.52 & 32.25 & 34.21 & 29.52 & 38.33 & 42.63 & 13.79 & 27.79 & 30.13 & 12.32 & 21.87 & 25.68 \\
\hline P-14 & 61.92 & -6.2 & 1.5 & 28.5 & 36.88 & 37.84 & 32.49 & 39.1 & 48.58 & 18.85 & 32.11 & 35.9 & 16.57 & 30.02 & 32.09 \\
\hline P-15 & 66 & -6.2 & 1.5 & 21.37 & 43 & 45.09 & 24.13 & 45.9 & 49.96 & 17.96 & 37.3 & 41.73 & 15.54 & 34.37 & 38.19 \\
\hline P-16 & 8.88 & -3.1 & 1.5 & 101.92 & 111.54 & 122.49 & 99.05 & 136.56 & 165.92 & 82.38 & 99.08 & 104.57 & 72.77 & 90.07 & 96.26 \\
\hline P-17 & 12.96 & -3.1 & 1.5 & 138.51 & 148.75 & 150.19 & 189.02 & 210.45 & 223.23 & 117.76 & 123.96 & 143.08 & 89.06 & 101.13 & 118.88 \\
\hline P-18 & 17.04 & -3.1 & 1.5 & 181.25 & 190.75 & 195.56 & 206.54 & 259.66 & 282.51 & 155.51 & 171.77 & 187.86 & 129.04 & 144.12 & 159.54 \\
\hline P-19 & 21.12 & -3.1 & 1.5 & 126.47 & 140.28 & 154.9 & 181.44 & 224.97 & 252.55 & 86.28 & 106.58 & 123.94 & 57.89 & 84.49 & 100.75 \\
\hline P-20 & 25.2 & -3.1 & 1.5 & 133.17 & 172.8 & 174.83 & 167.84 & 201.17 & 219.06 & 72.24 & 95.74 & 135.86 & 52.87 & 77.06 & 101.64 \\
\hline $\mathrm{P}-21$ & 29.28 & -3.1 & 1.5 & 218.16 & 240.8 & 260.45 & 210.55 & 252.8 & 269.51 & 142.01 & 161.75 & 238.29 & 78.68 & 107.23 & 183.1 \\
\hline P-22 & 33.36 & -3.1 & 1.5 & 144.12 & 175.29 & 181.3 & 211.04 & 255.31 & 274.82 & 112.25 & 153.99 & 163 & 69.49 & 112.74 & 130.76 \\
\hline P-23 & 37.44 & -3.1 & 1.5 & 158.02 & 166.1 & 177.81 & 162.24 & 191.79 & 211.63 & 97.33 & 118.14 & 136.55 & 64.05 & 87.52 & 100.71 \\
\hline $\mathrm{P}-24$ & 41.52 & -3.1 & 1.5 & 52.34 & 84.57 & 98.56 & 78.44 & 96.18 & 124.76 & 45 & 66.96 & 86.39 & 25.13 & 43.98 & 65.3 \\
\hline $\mathrm{P}-25$ & 45.6 & -3.1 & 1.5 & 51.29 & 77.95 & 84.69 & 67.5 & 89.59 & 95.21 & 34.13 & 55 & 73.5 & 19.27 & 29.07 & 50.63 \\
\hline P-26 & 49.68 & -3.1 & 1.5 & 6.3 & 24.47 & 47.3 & 17.34 & 48.57 & 77.09 & 4.36 & 14.37 & 27.11 & 4.39 & 14.03 & 26.77 \\
\hline $\mathrm{P}-27$ & 53.76 & -3.1 & 1.5 & 5.96 & 10.18 & 13.24 & 10.62 & 21.64 & 32.07 & 3.03 & 9.02 & 12.32 & 3.23 & 9.5 & 11.81 \\
\hline P-28 & 57.84 & -3.1 & 1.5 & 6.58 & 11.66 & 11.63 & 8.37 & 15.28 & 18.84 & 5.51 & 8.83 & 9.28 & 5.12 & 8.85 & 9.99 \\
\hline P-29 & 61.92 & -3.1 & 1.5 & 5.64 & 9.42 & 10.96 & 7.62 & 10.13 & 12.39 & 3.71 & 6.71 & 8.79 & 3.39 & 5.83 & 7.06 \\
\hline P-30 & 66 & -3.1 & 1.5 & 2.94 & 5.84 & 6.34 & 3.5 & 6.61 & 8.86 & 1.52 & 3.95 & 5 & 0.49 & 2.83 & 4.11 \\
\hline P-31 & 8.88 & 0 & 1.5 & 544.05 & 565.57 & 582.28 & 556.11 & 588.25 & 592.7 & 227.31 & 254.82 & 278.21 & 155.11 & 175.4 & 196.62 \\
\hline P-32 & 12.96 & 0 & 1.5 & 433.59 & 515.44 & 648.82 & 491.7 & 532.23 & 650.39 & 202.9 & 246.96 & 266.78 & 168.16 & 187.23 & 205.67 \\
\hline P-33 & 17.04 & 0 & 1.5 & 513.28 & 524.72 & 575.49 & 523.26 & 552.36 & 585.82 & 196.03 & 202.57 & 223.01 & 153.95 & 172.55 & $\begin{array}{l}191.8 \\
\end{array}$ \\
\hline P-34 & 21.12 & 0 & 1.5 & 304.46 & 397.54 & 451.36 & 314.87 & 413.93 & 471.06 & 210.11 & 235.97 & 264.5 & 175.09 & 185.5 & 207.4 \\
\hline P-35 & 25.2 & 0 & 1.5 & 281.21 & 285.84 & 295.2 & 294.7 & 318.9 & 352.89 & 149.33 & 192.37 & 209.08 & 112.39 & 151.21 & 177.73 \\
\hline P-36 & 29.28 & 0 & 1.5 & 187.81 & 201.81 & 237.01 & 192.22 & 216.94 & 266.04 & 137.88 & 159.88 & 185.42 & 123.3 & 137.8 & 160.2 \\
\hline P-37 & 33.36 & 0 & 1.5 & 149.1 & 158.54 & 189.61 & 158.17 & 182.6 & 204.37 & 114.32 & 137.64 & 161.7 & 97.31 & 111.05 & 133.31 \\
\hline P-38 & 37.44 & 0 & 1.5 & 150.5 & 158.96 & 162.77 & 170.34 & 180.41 & 197.38 & 93.94 & 112.74 & 143.16 & 78.87 & 97.19 & 117.11 \\
\hline P-39 & 41.52 & 0 & 1.5 & 94.26 & 105.34 & 121.81 & 102.19 & 123.71 & 131.97 & 74.39 & 95.38 & 111.09 & 46.2 & 57.97 & 89.43 \\
\hline P-40 & 45.6 & 0 & 1.5 & 77.78 & 87.59 & 105.75 & 82.61 & 93.95 & 113.38 & 50.26 & 65.54 & 92.31 & 38.24 & 58.51 & 78.34 \\
\hline P-41 & 49.68 & 0 & 1.5 & 82.52 & 126.57 & 174.97 & 94.48 & 146.12 & 191.58 & 64.55 & 77.06 & 105.43 & 26.41 & 56.88 & 86.34 \\
\hline P-42 & 53.76 & 0 & 1.5 & 37.75 & 78.36 & 91.47 & 45.14 & 87.3 & 104.03 & 27.07 & 30.43 & 55.53 & 17.27 & 24.84 & 42.66 \\
\hline P-43 & 57.84 & 0 & 1.5 & 23.38 & 35.44 & 51.95 & 28.24 & 53.54 & 75.39 & 15.64 & 19.8 & 28.29 & 7.05 & 16.37 & 23.1 \\
\hline P-44 & 61.92 & 0 & 1.5 & 20.84 & 29.16 & 34.12 & 13.16 & 36.52 & 44.63 & 14.06 & 18.49 & 27.21 & 8.47 & 15.11 & 21.05 \\
\hline P-45 & 66 & 0 & 1.5 & 4.82 & 5.05 & 6.56 & 5.74 & 7.9 & 9.21 & 2.08 & 3.12 & 5.76 & 1.13 & 2.64 & 4.81 \\
\hline P-46 & 8.88 & 3.1 & 1.5 & 167.68 & 192.84 & 231.45 & 179.79 & 205.23 & 276.26 & 43 & 54.56 & 63.05 & 29.54 & 37.2 & 42.64 \\
\hline P-47 & 12.96 & 3.1 & 1.5 & 219.42 & 232.65 & 242.45 & 242.49 & 262.7 & 296.46 & 46.59 & 57.21 & 66.05 & 32.84 & 42.18 & 54.57 \\
\hline P-48 & 17.04 & 3.1 & 1.5 & 265.76 & 283.15 & 297.32 & 281.96 & 312.17 & 354.68 & 44.54 & 55.41 & 64.01 & 30.68 & 40.07 & 52.57 \\
\hline P-49 & 21.12 & 3.1 & 1.5 & 321.64 & 350.59 & 385.54 & 359.29 & 385.66 & 420.76 & 83.69 & 107.04 & 125.34 & 69.54 & 86.13 & 100.18 \\
\hline P-50 & 25.2 & 3.1 & 1.5 & 225.91 & 277.65 & 375.93 & 273.75 & 295.65 & 394.19 & 78.81 & 97.47 & 118.72 & 57.97 & 79.64 & 97.74 \\
\hline P-51 & 29.28 & 3.1 & 1.5 & 215.13 & 248.94 & 295.53 & 237.05 & 261.15 & 310.18 & 82.86 & 104.02 & 128.63 & 52.34 & 71.94 & 100.56 \\
\hline P-52 & 33.36 & 3.1 & 1.5 & 251.4 & 277.83 & 320.72 & 267.4 & 296.33 & 348.84 & 99.82 & 130.99 & 169.03 & 65.96 & 89.55 & 121.48 \\
\hline P-53 & 37.44 & 3.1 & 1.5 & 159.73 & 178.49 & 192.4 & 177.82 & 194.65 & 237.58 & 116.2 & 156.38 & 178.1 & 84.14 & 117.51 & 132.71 \\
\hline P-54 & 41.52 & 3.1 & 1.5 & 130.86 & 152.2 & 185.51 & 142.12 & 188.13 & 208.29 & 89.44 & 108.39 & 137.14 & 58.97 & 71.84 & 103.96 \\
\hline P-55 & 45.6 & 3.1 & 1.5 & 94.38 & 126.59 & 152.25 & 100.12 & 144.63 & 165.15 & 44.33 & 75.3 & 97.15 & 27.65 & 51.3 & 79.84 \\
\hline P-56 & 49.68 & 3.1 & 1.5 & 43.13 & 65.38 & 88.35 & 71.22 & 87.15 & 103.23 & 22.74 & 42.69 & 64.12 & 12.21 & 22.41 & 45.9 \\
\hline P-57 & 53.76 & 3.1 & 1.5 & 32.8 & 42.6 & 57.63 & 40.41 & 50.78 & 71.26 & 16.93 & 31.63 & 48.94 & 8.44 & 14.82 & 26.72 \\
\hline P-58 & 57.84 & 3.1 & 1.5 & 12.79 & 21.55 & 31.47 & 15.38 & 30.72 & 41.27 & 10.84 & 18.56 & 24.88 & 3.34 & 11.75 & 17.55 \\
\hline P-59 & 61.92 & 3.1 & 1.5 & 9.83 & 11.38 & 19.37 & 10.35 & 14.66 & 21.16 & 5.32 & 10.19 & 17.67 & 0.68 & 3.44 & 10.31 \\
\hline P-60 & 66 & 3.1 & 1.5 & 1.72 & 8.76 & 10.98 & 4.26 & 10.4 & 11.85 & 0.62 & 3.63 & 6.44 & 0.21 & 2.36 & 7.34 \\
\hline P-61 & 8.88 & 6.2 & 1.5 & 55.73 & 61.03 & 75.06 & 68.47 & 83.44 & 100.32 & 14.64 & 36.31 & 59.87 & 11.91 & 20.76 & 40.74 \\
\hline P-62 & 12.96 & 6.2 & 1.5 & 57.42 & 67.66 & 77.51 & 72.12 & 95.56 & 104.41 & 13.33 & 31.76 & 52.23 & 5.51 & 16.69 & 26.2 \\
\hline P-63 & 17.04 & 6.2 & 1.5 & 63.72 & 72.66 & 82.98 & 74.28 & 96.25 & 110.15 & 27.63 & 38.79 & 51.28 & 11.97 & 22.49 & 38.99 \\
\hline P-64 & 21.12 & 6.2 & 1.5 & 88.47 & 91.44 & 108.06 & 93.89 & 101.81 & 114.98 & 42.9 & 76.14 & 88.89 & 21.96 & 42.21 & 61.69 \\
\hline P-65 & 25.2 & 6.2 & 1.5 & 58.44 & 63.91 & 77.22 & 79.76 & 89.4 & 97.13 & 24.42 & 43.8 & 55.76 & 14.51 & 28.94 & 41.73 \\
\hline P-66 & 29.28 & 6.2 & 1.5 & 44.44 & 57.95 & 65.78 & 55.94 & 79.73 & 85.6 & 23.15 & 42.7 & 49.42 & 13.94 & 27.61 & 38.27 \\
\hline P-67 & 33.36 & 6.2 & 1.5 & 42.28 & 45.8 & 59.75 & 56.59 & 80.95 & 89.74 & 20.45 & 32.1 & 41.99 & 10.56 & 21.05 & 33.8 \\
\hline P-68 & 37.44 & 6.2 & 1.5 & 43.37 & 54.04 & 62.13 & 59.13 & 66.24 & 78.65 & 22.13 & 31.79 & 41.3 & 10.3 & 20.79 & 31.78 \\
\hline P-69 & 41.52 & 6.2 & 1.5 & 35.54 & 45.57 & 64.17 & 46.23 & 61.25 & 81.05 & 17.61 & 25.06 & 36.05 & 9.25 & 16.61 & 25.47 \\
\hline P-70 & 45.6 & 6.2 & 1.5 & 33.9 & 40.49 & 51.91 & 40.45 & 51.88 & 64.04 & 12.36 & 19.66 & 24.46 & 5.69 & 10.78 & 16.24 \\
\hline P-71 & 49.68 & 6.2 & 1.5 & 25.45 & 31.39 & 41 & 30.22 & 40.33 & 50.98 & 10.76 & 17.18 & 21.09 & 4.14 & 8.28 & 15.23 \\
\hline P-72 & 53.76 & 6.2 & 1.5 & 20.69 & 27.32 & 34.76 & 21.16 & 30.23 & 40.92 & 9.21 & 14.42 & 19.24 & 3.07 & 7.14 & 12.13 \\
\hline P-73 & 57.84 & 6.2 & 1.5 & 11.06 & 19.34 & 24.76 & 12.12 & 20.17 & 28.91 & 7.4 & 12.76 & 15.42 & 2.05 & 6.09 & 10.16 \\
\hline P-74 & 61.92 & 6.2 & 1.5 & 9.21 & 11.47 & 17.74 & 10.1 & 14.14 & 20.93 & 5.56 & 9.24 & 11.82 & 0.04 & 2.07 & 5.14 \\
\hline
\end{tabular}

